\title{
The relationship between the predictors of obstructive sleep apnea and difficult intubation
}

\author{
Sang-Jun Lee, Jong Nam Lee, Tae-Sung Kim, and Young-Chul Park \\ Department of Anesthesiology and Pain Medicine, Busan St. Mary's Hospital, Busan, Korea
}

Background: The study was performed in order to determine the risk factors for difficult tracheal intubation in obstructive sleep apnea patients.

Methods: For 115 male patients with obstructive sleep apnea syndrome and who were undergoing palatal muscle resection (PMR), we investigated the correlation between their age, height, weight, body mass index (BMI), their Epworth Sleepiness Scale (ESS), their apnea-hypopnea index (AHI), their neck circumference and the difficulty of tracheal intubation.

Results: The factors significantly related to difficult tracheal intubation in obstructive sleep apnea patients were a high AHI and a large neck circumference. There was no significant correlation between weight, BMI, arterial hypertension, ESS and difficult tracheal intubation in obstructive sleep apnea patients.

Conclusions: In this study, a high AHI and a large neck circumference can predict difficult tracheal intubation in obstructive sleep apnea patients. (Korean J Anesthesiol 2011; 60: 173-178)

Key Words: Difficult intubation, OSAS.

\section{Introduction}

Obstructive sleep apnea syndrome (OSAS) is the next most common disorder after asthma [1], it causes sleep disorders and hypoxia because of the trembling of the pharyngeal wall and palate when inspiring due to the repetitive, partial or complete obstruction of the pharynx [2]. Without proper sleep, the patient may experience excessive daytime sleepiness (EDS), headache, change in behavior, reduced intelligence and even personality change [3]. Furthermore, it may be the cause of severe complications such as hypertension, pulmonary hypertension, cardiac arrhythmia and congestive heart failure [4-6].

OSAS is commonly accompanied by factors such as the thickening of the tonsil and adenoid, obesity and mandibular hypoplasia, and the upper airway obstruction may worsen in such cases [4]. When inducing general anesthesia during palatal muscle resection (PRM) [6] to treat such OSAS patients, and the maintenance of mask ventilation may be difficult due to the airway obstruction from the reduced pharyngeal muscle tension $[7,8]$, and intubation may be difficult due to

Received: June 8, 2010. Revised: 1st, June 26, 2010; 2nd, July 10, 2010. Accepted: August 2, 2010.

Corresponding author: Jong Nam Lee, M.D., Department of Anesthesiology and Pain Medicine, Busan St. Mary's Hospital, 538-41, Yonghodong, Nam-gu, Busan 608-838, Korea. Tel: 82-51-933-7363, Fax: 82-51-932-8600, E-mail: djklush@hanmail.net

(c) This is an open-access article distributed under the terms of the Creative Commons Attribution Non-Commercial License (http:// creativecommons.org/licenses/by-nc/3.0/), which permits unrestricted non-commercial use, distribution, and reproduction in any medium, provided the original work is properly cited. 
the abnormalities of the face or the upper airway [9]. Such a difficult intubation can be the main factor leading to increased morbidity and an increased death rate $[10,11]$.

We report here on the effects of the predictors of OSAS (which is the morbidity due to hypertension, habitual snoring, apnea observed during sleep, choking during sleep, the abnormal structure of the upper airway, a thick neck circumference and moderate obesity $[12,13])$ according to the difficulty of performing intubation for general anesthesia.

\section{Materials and Methods}

One hundred fifteen ASA class I \& II male patients were chosen for this study and they were diagnosed with sleep apnea in the Departments of Internal Medicine and ENT and they underwent PMR under general anesthesia because they failed to respond to medicinal treatment. The authors obtained the permission from the hospital's ethics committee and we obtained informed written consent from the patients after the objectives of the study were explained to them. Before the surgery, the patient's age, height, weight and level of obesity (as the body mass index [BMI]) were recorded. The neck circumference was recorded at the level of the thyroid cartilage. A polysomnography was performed on all the patients for one night. Apnea was defined as when respiration completely stopped for $10 \mathrm{sec}$ or more while there was still respiratory movement. Hypopnea was defined as at least a $50 \%$ decrease of the respiration amplitude, and this was accompanied by a clear decrease of the tidal volume for at least $10 \mathrm{sec}$, EEG arousal and a decrease in oxygen saturation by $4 \%$ or more [14]. The apneahypopnea index (AHI) is the mean sum of the occurrences of apnea and hypopnea for every hour of sleep where an AHI < 5 is for patients who only snore and who do not complain of excessive daytime sleepiness (EDS) during the day: $5 \leq$ AHI $<$ 15 for the patients with mild sleep apnea, $15 \leq \mathrm{AHI}<30$ for the patients with moderate sleep apnea and an AHI $\geq 30$ for the patients with severe sleep apnea [14]. Another method uses larger ranges as $5 \leq \mathrm{AHI}<25$ for the patients with mild sleep apnea, $25 \leq \mathrm{AHI}<50$ is for the patients with moderate sleep apnea and an $\mathrm{AHI} \geq 50$ is for patients with severe sleep apnea $[15,16]$. Before surgery the patients were asked to complete the AHI and Epworth Sleepiness Scale (ESS) (Table 1). The ESS is a subjective scale where the patient grades his excessive daytime sleepiness (EDS) from 0 to 3 in 8 specific situations, such as while sitting and reading a book or watching TV. If the total score for the 8 situations is 10 or higher, then the patient is considered to have EDS [17].

On the day the nocturnal polysomnography (NPSG) was taken, if the systolic blood pressure, which was taken 3 times, was $140 \mathrm{mmHg}$ or above or if the diastolic blood pressure was $90 \mathrm{mmHg}$ or above, then the patient was considered to have hypertension. After the patient had been lying down and was stabilized, the blood pressure was taken 3 times with 10 minute intervals.

No premedication was given that had sedatives. Thirty minutes prior to entering the OR, $0.2 \mathrm{mg}$ IM glycopyrrolate was administered. Standard EKG electrodes, a noninvasive automatic blood pressure monitor and a pulse oximeter were placed. After waiting 5 minutes for the patient to stabilize, the blood pressure and pulse rate were taken before anesthetic induction. After the patient was seated comfortably, the patient was made to sit up and sick out his tongue as far as he could in order to observe the internal structure of the pharynx under lighting. Mallampati et al. [18] classified the pharyngeal structure into 3 types, but Samsoon and Young [19] created a modified Mallampati test (MMT) that divides the structure into

\begin{tabular}{|c|c|c|c|c|}
\hline \multirow[b]{2}{*}{ Situation } & \multicolumn{4}{|c|}{ Chance of dozing } \\
\hline & $\begin{array}{l}\text { Never } \\
(0)\end{array}$ & $\begin{array}{l}\text { Slight chance of } \\
\text { dozing } \\
\text { (1) }\end{array}$ & $\begin{array}{l}\text { Moderate chance of } \\
\text { dozing } \\
\text { (2) }\end{array}$ & $\begin{array}{l}\text { High chance of } \\
\text { dozing } \\
\text { (3) }\end{array}$ \\
\hline 1. Sitting and reading & $\square$ & $\square$ & 口 & $\square$ \\
\hline 2. Watching TV & $\square$ & $\square$ & $\square$ & $\square$ \\
\hline 3. Sitting, inactive in a public place & $\square$ & $\square$ & $\square$ & $\square$ \\
\hline 4. As a passenger in a car for an hour without making any stops & $\square$ & $\square$ & $\square$ & $\square$ \\
\hline 5. Lying down to rest in the afternoon when circumstances permit & $\square$ & $\square$ & 口 & $\square$ \\
\hline 6. Sitting and talking to someone & 口 & & 口 & $\square$ \\
\hline 7. Sitting quietly after a lunch without alcohol & $\square$ & & 口 & $\square$ \\
\hline \multirow[t]{2}{*}{ 8. In a car, while stopping for a few minutes in the traffic } & $\square$ & $\square$ & $\square$ & $\square$ \\
\hline & \multicolumn{4}{|c|}{ Score } \\
\hline
\end{tabular}


4 types. Class I is when the soft palate, the fauces, the uvula and the anterior and posterior tonsillar pillars are visible. Class II is where all the Class I structures are visible except for the tonsillar pillars. Class III is where only the base of the uvula is visible. Class IV is where the uvula cannot be seen and only the soft palate is visible.

Anesthesia was performed by a skilled anesthesiologist. For denitrogenization, $100 \%$ oxygen $5 \mathrm{~L} / \mathrm{min}$ for $2-3 \mathrm{~min}$ was given by a mask and this was aspired by voluntary respiration. Propofol $(10 \mathrm{mg} / \mathrm{ml})$ and remifentanil $(50 \mu \mathrm{g} / \mathrm{ml})$ were administered by a TCI pump (OrchestraTM, Fresenius Vial, France). The Minto model was chosen for remifentanil and the Schnider model was chosen for propofol. Propofol was set at a target effect site concentration of $4.0 \mu \mathrm{g} / \mathrm{ml}$. Remifentanil was set at a target effect site concentration of $3.0 \mathrm{ng} / \mathrm{ml}$. Propofol was administered after administering remifentanil and the target effect site concentration reached $3.0 \mathrm{ng} / \mathrm{ml}$. After loss of consciousness was observed in the patient, $0.6 \mathrm{mg} / \mathrm{kg}$ rocuronium (a muscle relaxant) was administered IV. After about 2 minutes when the state of muscle relaxation was observed, the head was placed in the sniffing position to facilitate intubation. Then a size- 3 curved laryngoscope was used to maximize exposure of the glottis, and without pressing the thyroid cartilage, the airway was evaluated and graded following Cormack and Lehane's grading system [20]. Cormack and Lehane proposed grading the laryngoscopic view from grade I to grade IV. Grade I is when the epiglottis and vocal cords are completely exposed. Grade II is when only the rear of the vocal cords can be seen. Grade III is when only the epiglottis is exposed. Grade IV is when only the soft palate can be seen. After intubation, mechanical ventilation was performed with

Table 2. Demographic Data

\begin{tabular}{lccc}
\hline \multicolumn{1}{c}{ Variable } & $\begin{array}{c}\text { Group D } \\
(\mathrm{n}=23)\end{array}$ & $\begin{array}{c}\text { Group E } \\
(\mathrm{n}=92)\end{array}$ & P value \\
\hline Age $(\mathrm{yr})$ & $38.8 \pm 11.7$ & $38.1 \pm 12.3$ & NS \\
Height $(\mathrm{cm})$ & $170.8 \pm 6.9$ & $169.5 \pm 5.5$ & NS \\
Weight $(\mathrm{kg})$ & $76.9 \pm 9.7$ & $74.1 \pm 9.3$ & NS \\
BMI $\left(\mathrm{kg} / \mathrm{m}^{2}\right)$ & $27.3 \pm 2.4$ & $26.9 \pm 3.2$ & NS \\
Arterial hypertension [n (\%)] & $10(43)$ & $39(42)$ & NS \\
Modified Mallampati test & & & \\
$\quad$ Classes I and II [n (\%)] & $6(26.1)$ & $41(44.6)$ & NS \\
$\quad$ Classes III and IV [n (\%)] & $17(73.9)$ & $51(55.4)$ & NS \\
Neck circumference (cm) & $43.9 \pm 2.5$ & $38.8 \pm 3.7$ & 0.014 \\
ESS score & $9.34 \pm 4.58$ & $9.15 \pm 3.36$ & NS \\
AHI & $49.3 \pm 19.5$ & $28.9 \pm 18.0$ & 0.008 \\
\hline
\end{tabular}

The data is expressed as means \pm SDs. Group D: obstructive sleep apnea patients with difficult intubation. Group E: obstructive sleep apnea patients without difficult intubation. BMI: body mass index, ESS: Epworth Sleepiness Scale, AHI: apnea-hypopnea index, NS: not significant. The results are presented as means \pm SDs or as percentages. oxygen at $2 \mathrm{~L} / \mathrm{min}$, carbon dioxide at $2 \mathrm{~L} / \mathrm{min}$, the tidal volume was $9 \mathrm{ml} / \mathrm{kg}$ and the tidal rate was $12 \mathrm{bpm}$.

Group E, for whom the intubation was easy, was limited to the patients with a Cormack and Lehane grade of I and II (the glottis was immediately visible). Group D, for whom the intubation was difficult, was for the patients given a Cormack and Lehane grade of III or IV (poor visibility of the glottis) [21]. All the values are shown as means \pm SDs and as percentages. Independent samples t-tests, crosstabulation and chi square tests were used for comparing the two groups. P values $<0.05$ were considered significant. Ultimately, a comprehensive evaluation was done by binary logistic regression analysis and a multivariate test to see the effects of each independent variable on the dependent variables.

\section{Results}

The test results showed that of the 115 OSAS patients who underwent PMR, Group E consisted of 92 patients (80\%) and Group D consisted of 23 patients (20\%). There were no significant differences in the age, height, weight, BMI, hypertension or the rate of the prevalence among the OSAS patients (Table 2).

Among the OSAS patients, the patients with MMT Classes III and IV made up $73.9 \%$ of Group D, which was greater than the $55.4 \%$ in Group E. The neck circumference in Group D was 43.9 $\pm 2.5 \mathrm{~cm}$, which was a larger value than $38.8 \pm 3.7 \mathrm{~cm}$ in Group E $(\mathrm{P}=0.014)$ (Table 2).

The AHI, which shows the severity of OSAS, was $49.3 \pm 19.5$ for Group D, and this was greater than $28.9 \pm 18.0$ for Group E (P $=0.008$ ). However, there was no significant difference found in the ESS score, which is a subjective test for sleep apnea (Table 2).

Seventy percent of the Group D patients had neck circumferences $\geq 40 \mathrm{~cm}$, whereas only $35 \%$ of the Group E patients had neck circumferences $\geq 40 \mathrm{~cm}(\mathrm{P}=0.014)$. Also, $61 \%$ of the Group D patients had an AHI $\geq 50$, but only $32 \%$ of the Group E patients had an $\mathrm{AHI} \geq 50(\mathrm{P}=0.038)$ (Table 3$)$.

Table 3. Demographic Data

\begin{tabular}{lrrr}
\hline \multicolumn{1}{c}{ Variable } & $\begin{array}{c}\text { Group D } \\
(\mathrm{n}=23)\end{array}$ & $\begin{array}{c}\text { Group E } \\
(\mathrm{n}=92)\end{array}$ & P value \\
\hline $\begin{array}{l}\text { Neck Circumference } \\
\quad<40\end{array}$ & $7(30 \%)$ & $60(65 \%)$ & 0.004 \\
$\quad$ & $16(70 \%)$ & $32(35 \%)$ & \\
$\quad \begin{array}{l}\text { Apnea-hypopnea index (AHI) } \\
\quad<50\end{array}$ & $9(39 \%)$ & $63(68 \%)$ & 0.015 \\
$\quad \geq 50$ & $14(61 \%)$ & $29(32 \%)$ & \\
\hline
\end{tabular}

The data is expressed as numbers (percentages). Group D: obstructive sleep apnea patients with difficult intubation. Group E: obstructive sleep apnea patients without difficult intubation. 
Table 4. The Results of Binary Logistics Regression Analysis between the Demographic Characteristics and the Groups

\begin{tabular}{lcccc}
\hline \multirow{2}{*}{$\begin{array}{l}\text { Independent } \\
\end{array}$} & $\mathrm{P}$ & $\begin{array}{l}\text { Odds } \\
\text { ratio }\end{array}$ & \multicolumn{2}{c}{$\begin{array}{c}\text { 95\% Confidence } \\
\text { interval of the } \\
\text { odds ratio }\end{array}$} \\
\cline { 3 - 5 } & & & Lower & Upper \\
\hline BMI & 0.839 & 1.065 & 0.578 & 1.962 \\
Arterial hypertension & 0.876 & 1.130 & 0.245 & 5.212 \\
MMT classes I and II & 0.254 & 0.404 & 0.085 & 1.918 \\
ESS score & 0.159 & 0.669 & 0.382 & 1.171 \\
AHI & 0.005 & 1.124 & 1.036 & 1.221 \\
Neck circumference & 0.000 & 1.764 & 1.290 & 2.411 \\
Constant & 0.014 & 0.000 & & \\
\hline
\end{tabular}

BMI: body mass index, MMT: Modified mallampati test, ESS: Epworth Sleepiness Scale, AHI: apnea-hypopnea index.

The results of the logistic regression analysis showed that for the sleep apnea patients, the AHI and neck circumference were the variables affecting difficult intubation $(\mathrm{P}<0.05)$. As the AHI increased, the probability of belonging to Group D went up 1.124 times (the $95.0 \%$ confidence interval of the odds ratio was 1.036 and 1.221) (Table 4). As the neck circumference increased, the probability of belonging to Group D went up 1.764 times (the $95.0 \%$ confidence interval of the odds ratio was 1.290 and 2.411) (Table 4). Thus, the variables affecting the probability of belonging to Group D were a high AHI and large neck circumference, and the neck circumference had the highest effect.

\section{Discussion}

Charles Kite was the first to describe intubation with difficult airway maintenance in 1788 [22]. Since then, there have been ongoing developments in the methods of intubation. Yet difficult intubation in general anesthesia has remained a main concern for anesthesiologists. Difficult intubation is especially frequent in OSAS patients $[23,24]$ and it is one of the main causes of increased morbidity and mortality rates [10,11].

The first reason that difficult intubation occurs in OSAS patients is that many OSAS patients have retrognathia, short and thick necks, and frequent abnormal facial and upper airway structures such as a large tongue, which all increase the danger of difficult intubation [9]. Of the OSAS patients in the present study and in whom intubation was difficult according to the Cormack and Lehane grading, there were 21 grade III (18.3\%) patients and 2 patients grade IV (1.7\%) patients. In the presented study, one of the two Group D patients with a Cormack and Lehane Grade of IV had successful intubation after the cricoid cartilage area was pressed and 1-3 attempts were made with a probe. A light wand was used in one patient with a Cormack and Lehane Grade of IV, and intubation was successful after 4 attempts. Lewis et al. [21] stated that intubation is difficult in patients with a Cormack and Lehane grade of III and IV, which is defined based on the exposure of the larynx. Further, one report stated that grade III patients may face great difficulty to be intubated, and in the grade IV patients, intubation is complicated without the help of special aiding methods [25]. Therefore, before general anesthesia, analyzing and predicting the risk factors that affect difficult intubation is critical for OSAS patients. For the patients who are suspected of having sleep apnea, a thorough evaluation of the upper airway at a pre-surgery visit or before anesthesia induction must be performed, and evaluation of the predictors of OSAS must be performed first. According to the other reports on this subject, hypertension, habitual snoring, apnea during sleep, choking during sleep, an anthropometrical upper airway structure, a thick neck circumference and moderate obesity are known to be significant predictors for OSAS [26]. One study reported there is also a significant relationship between the BMI and OSAS [27].

The second reason that difficult intubation occurs in OSAS patients is due to their short necks and obesity [28]. Difficult intubation occurs when the $\mathrm{BMI}$ is high, the neck circumference is large and the Mallampati score is $\geq 3$ [29]. The level of obesity can be assessed from the BMI. The BMI of an average man is around 22 and the BMI for the average woman is around 20. A man with a BMI of $\geq 27$ is considered obese [30]. The authors found the BMIs of 115 patients were on average $27.0 \pm 2.7$, which showed that most of the OSAS patients belonged to the obese category $[3,29]$. Yet among the OSAS patients, there was no significant difference in the BMI of the patients with difficult intubation compared to the BMI of the patients without difficult intubation. Although obesity may be related to difficult intubations [31], since most of the OSAS patients were obese, it is assumed that the difference in BMI among the OSAS patients did not act as a significant risk factor affecting the difficulty of intubation.

In a report based on patients in the West, the danger of OSAS was reported to be high when the neck circumference for men was $\geq 43 \mathrm{~cm}$ and that for women was $\geq 40 \mathrm{~cm}$ [32]. However, for Asians, in contrast to the rule above, the occurrence rate of OSAS significantly increases if the neck circumference is $\geq$ $40 \mathrm{~cm}$ irrespective of gender [26]. The neck circumference of Group D in the present study was $43.9 \pm 2.5 \mathrm{~cm}$ and that for Group E was $38.8 \pm 3.7 \mathrm{~cm}$. For patients with difficult intubation, their neck circumferences were significantly thicker $(\mathrm{P}=0.014)$. Moreover, $70 \%$ of the patients with difficult intubations had neck circumferences $\geq 40 \mathrm{~cm}$. Only $35 \%$ of the patients with easy intubation had a neck circumference $\geq 40 \mathrm{~cm}$. Thus, the factor that most influenced the difficulty of intubations in OSAS patients was the thickness of the neck. Forty $\mathrm{cm}$ or above can especially be considered a significant risk factor.

The severity of OSAS, the AHI (which can be determined via 
polysomnography) and the subjective ESS score are also known to be main predictors of OSAS [23]. In the present study, difficult intubation in OSAS patients and a high AHI were correlated. Sixty one percent of the moderate sleep apnea patients who had an AHI of $\geq 50$ had difficult intubations and only $32 \%$ had easy intubations (Table 3). Therefore, for OSAS patients scheduled for PMR and who have an $\mathrm{AHI} \geq 50$ (which is for severe sleep apnea), thorough preparation prior to anesthesia must be done for difficult intubation and other related risks.

However, the ESS score, which is a patient-subjective sleep apnea test, did not show a significant relation with difficult intubation in OSAS patients. This may be because of the subjectivity involved and the difficulty for patients to objectively measure themselves may have created errors. This lack of significance may have resulted from an anatomically abnormal upper airway having less direct relevance as compared to that of the AHI.

Predicting difficult intubation and airway management is necessary. For average patients, the BMI and weight are known to be predictive factors for difficult intubation, but their significance as predictors in the present study was low. However, even in the OSAS patients, the predictors of difficult intubation were a high Mallampati score and a high AHI, and the neck circumference also worked as a risk factor for difficult intubation. If the Mallampati score is $\geq 3$, the AHI is $\geq 50$ and the neck circumference is $\geq 40 \mathrm{~cm}$, then it can be predicted that intubation will be difficult, so thorough preparations must be made for such cases.

First, one must be careful in choosing the drugs for anesthesia induction. Most OSAS patients are sensitive to the sedatives used for anesthesia induction. In anesthesia induction, the worst case scenario for an anesthesiologist can occur, such as when ventilation does not work and intubation is impossible, so it is recommended to use drugs with a short onset time. Also, depending on the situation, intubation using awake fiberoptic bronchoscopy and retrograde intubation can be useful in OSAS patients [5].

Second, steroids can be preventively used to avoid airway obstruction that can occur after surgery. Preparation for emergency bronchotomy along with the use of a monitoring device such as a pulse-oximeter and an oxygen supply of the appropriate concentration would be advisable.

A high AHI (which is most closely-related to the severity of OSAS), polysomnography and a thick neck can be the predictors of difficult intubation in OSAS patients. Polysomnography and the neck thickness can be obtained from the basic medical records of OSAS patients. Especially for patients in whom PMR is performed, polysomnography has become mandatory. So observing the upper airway evaluations, the AHI (which reflects the severity of OSAS) and the neck thickness can help predict difficult intubation.

\section{References}

1. McNicholas WT, Levy P. Sleep-related breathing disorders: definitions and measurements. Eur Respir J 2000; 15: 988-9.

2. Barash PG, Cullen BF, Stoelting RK. Clinical anesthesia. Philadelphia, JB Lippincott Co. 1989, pp 1120-1.

3. Boushra NN. Anaesthetic management of patients with sleep apnoea syndrome. Can J Anaesth 1996; 43: 599-616.

4. Hanning CD. Obstructive sleep apnoea. Br J Anaesth 1989; 63: 47788.

5. Shin WJ, Cheong MA, Yeom JH, Kim HS, Kim YC, Lee DH, et al. The analysis of anesthetic management in the 28 obstructive sleep apnea patients who had undergone uvulopalatopharyngoplasty under the general anesthesia. Korean J Anesthesiol 1998; 34: 17581.

6. Kim TH, Koo SK, Han CW, Kim YC, Ahn GY. Palatal muscle resection (PMR) for the treatment of snoring patients. Korean J Otorhinolaryngol-Head Neck Surg 2008; 51: 1119-23.

7. Gabrielczyk MR. Acute airway obstruction after uvulopalatopharyngoplasty for obstructive sleep apnea syndrome. Anesthesiology 1988; 69: 941-3.

8. Kadota Y, Imabayashi T, Gushiken T, Kawasaki K, Oda T, Yoshimura N. Pulmonary edema due to acute airway obstruction immediately after tracheal extubation. Masui 1998; 47: 1333-7.

9. Hung J, Whitford EG, Parsons RW, Hillman DR. Association of sleep apnoea with myocardial infarction in men. Lancet 1990; 336: 261-4.

10. Cobley M, Vaughan RS. Recognition and management of difficult airway problems. Br J Anaesth 1992; 68: 90-7.

11. Connolly LA. Anesthetic management of obstructive sleep apnea patients. J Clin Anesth 1991; 3: 461-9.

12. Flemons WW, Whitelaw WA, Brant R, Remmers JE. Likelihood ratios for a sleep apnea clinical prediction rule. Am J Respir Crit Care Med 1994; 150: 1279-85.

13. Maislin G, Pack AI, Kribbs NB, Smith PL, Schwartz AR, Kline LR, et al. A survey screen for prediction of apnea. Sleep 1995; 18: 158-66.

14. Sleep-related breathing disorders in adults: recommendations for syndrome definition and measurement techniques in clinical research. The Report of an American Academy of Sleep Medicine Task Force. Sleep 1999; 22: 667-89.

15. Nakata S, Noda A, Yangai E, Suzuki K, Misawa H, Nakashima T. Results of tonsillectomy for obstructive sleep apnea syndrome in adults with tonsillar hypertrophy. Int Congr Ser 2003; 1257: 95-8.

16. O'Connor C, Thornley KS, Hanly PJ. Gender differences in the polysomnographic features of obstructive sleep apnea. Am J Respir Crit Care Med 2000; 161: 1465-72.

17. Yun CH. A diagnosis and treatment of obstructive sleep apnea syndrome. J Korean Sleep Soc 2004; 1: 34-40.

18. Mallampati SR, Gatt SP, Gugino LD, Desai SP, Waraksa B, Freiberger D, et al. A clinical sign to predict difficult tracheal intubation: a prospective study. Can Anaesth Soc J 1985; 32: 429-34.

19. Samsoon GL, Young JR. Difficult tracheal intubation: a retrospective study. Anaesthesia 1987; 42: 487-90.

20. Cormack RS, Lehane J. Difficult tracheal intubation in obstetrics. Anaesthesia 1984; 39: 1105-11. 
21. Lewis M, Keramati S, Benumof JL, Berry CC. What is the best way to determine oropharyngeal classification and mandibular space length to predict difficult laryngoscopy? Anesthesiology 1994; 81: 69-75.

22. Brandt L. The first reported oral intubation of the human trachea. Anesth Analg 1987; 66: 1198-9.

23. Hiremath AS, Hillman DR, James AL, Noffsinger WJ, Platt PR, Singer SL. Relationship between difficult tracheal intubation and obstructive sleep apnoea. Br J Anaesth 1998; 80: 606-11.

24. Siyam MA, Benhamou D. Difficult endotracheal intubation in patients with sleep apnea syndrome. Anesth Analg 2002; 95: 1098102.

25. Practice guidelines for management of the difficult airway. A report by the American Society of Anesthesiologists Task Force on Management of the Difficult Airway. Anesthesiology 1993; 78: 597602.

26. Kong HW, Lee HJ, Choi YS, Rha JH, Ha CK, Hwangc DU, et al. Clinical predictors of obstructive sleep apnea. J Korean Neurol Assoc 2005; 23: 324-9.
27. Seo WS, Son HI, Koo BH, Lee KH, Song CJ, Kwak KP, et al. Clinical features of Korean obstructive sleep apnea syndrome and usefulness of Korean version of epworth sleepiness scale. J Korean Soc Biol Ther Psychiatry 2005; 11: 150-7.

28. Chung F, Crago RR. Sleep apnoea syndrome and anaesthesia. Can Anaesth Soc J 1982; 29: 439-45.

29. Gonzalez H, Minville V, Delanoue K, Mazerolles M, Concina D, Fourcade O. The importance of increased neck circumference to intubation difficulties in obese patients. Anesth Analg 2008; 106: 1132-6.

30. Yao FF. Yao and Artusio's Anesthesiology: Problem Oriented Patient Management. 4th ed. Philadelphia, Lippincott-Raven. 1998, pp 1001-18.

31. Wilson ME, Spiegelhalter D, Robertson JA, Lesser P. Predicting difficult intubation. Br J Anaesth 1988; 61: 211-6.

32. Schellenberg JB, Maislin G, Schwab RJ. Physical findings and the risk for obstructive sleep apnea. The importance of oropharyngeal structures. Am J Respir Crit Care Med 2000; 162: 740-8. 